\title{
Study on How to Improve Media Literacy in College Foreign Language Teaching in the New Era
}

\author{
Gao Yanjun ${ }^{1, \text { a }}$
}

\author{
${ }^{1}$ Shandong Technology and Business University \\ a18563891570@163.com
}

\begin{abstract}
Nowadays, the number of foreign language graduates in colleges and universities transforming into the field of media is on the rise, which is attributed to the rapid development of the emerging media industry and the strong demand for international media talents. In view of this social phenomenon, college foreign language teaching should also keep pace with the times, actively incorporate media literacy education into the training system, improve students' media literacy in multiple ways, and constantly export international media talents to the society on the basis of foreign language plus media.
\end{abstract}

Keywords: New era, college foreign language, media literacy

\section{INTRODUCTION}

With the arrival of the omnimedia era, numerous communication means and channels have been deeply integrated into and comprehensively covered people's living space, thus giving birth to the rapid development of the media industry in multiple fields and directions [1]. In this context, the number of college foreign language graduates who change their majors to media majors or pursue further education is on the rise. Students with foreign language major background have their own advantages to work in the field of media, and the promotion of students' media literacy in foreign language teaching also meets the requirements of the development of higher education today [2]. Therefore, foreign language teaching in colleges and universities should make concerted efforts from five aspects: personnel training plan, teacher team construction, media theory and practice, media cultivation environment and basic humanistic quality, form a multi-channel, integrated and promoted development mode, and constantly improve students' media literacy, so as to meet the strong demand for international media interdisciplinary talents.

\section{THE INCREASING NUMBER OF FOREIGN LANGUAGE GRADUATES WHO TRANSFER TO MEDIA MAJORS IN THEIR FURTHER STUDY}

The foreign language major is one of the most traditional majors in China's colleges and universities. Since the reform and opening up, great achievements have been made in foreign language education, which has provided strong talent support for China to connect with the world and let the world understand China, and made indelible contributions. Today, the development of Internet technology has made the physical walls between countries disappear. With the arrival of the new era of omnimedia, the world has changed from a world to a village, thus forming the concept of "global village". With the development of science and technology, the traditional foreign language major faces many challenges and even crises. With the rise of artificial intelligence, domestic technology companies represented by iFlytek have made rapid progress in speech recognition and real-time translation, which makes many colleges and universities have to train interdisciplinary talents with "foreign language plus" as the feature in the cultivation of foreign language talents to increase the competitiveness of foreign language graduates in the job market [3].

Nowadays, the employment situation of undergraduate graduates is more and more severe, and 
the entrance examination for postgraduate education has become the choice of many college students. In recent years, the entrance examination for postgraduate education has become a great boom. In 2021, the number of students taking the entrance examination for postgraduate education reached a record high of 3.77 million. For undergraduates in foreign language majors, in recent years, the proportion of cross-major postgraduate entrance examination has been increasing year by year. The cross-major is shown in the following four major fields: International Chinese Language Education, Master of Law, Economics and Management, and Journalism and Communication. Among them, the application rate of Journalism and Communication is increasing year by year. Radio, broadcasting and new media need a large number of foreign language announcers, journalists, sports commentators and other international communication talents. According to statistics, the demand for media talents in China is growing at a rapid rate of $20 \%$.

\section{SOME ADVANTAGES OF FOREIGN LANGUAGE GRADUATES TRANSFERRED TO MEDIA MAJOR FOR ADVANCED STUDIES}

There are several reasons why the media major has become the preferred major for foreign language majors to further their studies.

First, it can give full play to the advantages of linguistics major. Foreign language major students deal with language all day long. In the process of switching between Chinese and foreign language, their language comprehension and application ability are constantly strengthened. Today, language is no longer confined to the scope of mere linguistic theory, but the basis for the effective rationalization of all communication and norms. It has the function of communication, the function of interpersonal understanding and interpersonal relationship construction to connect different subjects together internally. For media practitioners, language ability is one of the most important basic skills. No matter how good the news is, no matter how good the perspective is, no matter how good the thought is, it needs to be presented through language organization.

Second, the double major background of foreign language plus media will have a wider range of career choices. Cross-major entrance examination for graduate school will increase the difficulty coefficient for students. In addition to the rapid development of the media field, the reason why students with foreign language background choose to transform to the media field is that first, unlike the medical, agricultural, science and engineering majors, the media major has higher professional barriers. Especially for the hot new media industry today, they pay more attention to the professional ability and work experience of practitioners. Second, many traditional radio and television media with the property of public institutions, such as CCTV, Xinhua News Agency, People's Daily, Dazhong Daily and so on, often require applicants to have a master's degree or above. Even in the new media industry with relatively loose educational requirements, it is an indisputable fact that BTA and other giant Internet companies still value educational qualifications. Therefore, the benefit of a master's degree will increase the range of career choices for students.

Third, a foreign language major has a huge advantage in the field of international media. The media industry often has clear requirements on foreign language skills for employees, especially in international communication, foreign publicity work, foreign correspondents and other industries. For example, Beijing Foreign Studies University, Shanghai International Studies University, University of Foreign Studies and Sichuan International Studies University are known as the cradle of diplomats. For example, CCTV's chief correspondent in the United States, Wang Guan, won the first prize of the 21st Century Cup National College Students' English Speech Contest. Yu Jia, the host of CCTV's NBA Frontier, and Ke Fan, the anchor of Tencent's NBA basketball program, were all English majors. Today, Internet new media companies such as Douyin, Toutiao and Kuaishou have their own global market. Many media companies have set up overseas and foreign editions, and have a huge user base around the world. Only by mastering foreign languages can one "tell Chinese stories well". Cross-cultural communication ability is the precondition for international communication localization. Moreover, with the implementation of the "Belt and Road Initiative" national strategy, not only English, but also small language editing talents have become scarce positions for some media, and the corresponding talent demand is growing rapidly.

\section{THE NECESSITY OF IMPROVING MEDIA LITERACY IN COLLEGE FOREIGN LANGUAGE TEACHING}

Media literacy, also known as communication literacy and media quality, refers to the ability to use, understand and produce media information in various situations, or people's ability to choose, understand, question, evaluate, create and produce media information, as well as the ability to think and react. Media literacy can be roughly divided into three aspects, namely understanding, using and participating in the media. First of all, the cognition of media is the core of media literacy, which includes the nature, characteristics and types of media, as well as the functions and functions of media and the rights and obligations of media audiences. Second, the use of the media shows 
that the audience can use the media to obtain information, absorb knowledge, express opinions, enjoy art and entertainment. Third, the participation of the media should not only have the awareness of participation, but also have the ability to participate, and can use modern communication tools to provide valuable information and opinions to the media, rather than useless or wrong.

For students who intend to move from foreign language major to media field, it is especially necessary to improve their media literacy. The significance is twofold. First, the promotion of media literacy is an important foundation for students to work in the field of media. Nowadays college students know, use and participate in media activities all the time. In the process of activities, students will gradually learn to use the media and the ability to make media content, such as Internet surfing, interpreting media content such as information, pictures, scenes, story, as well as activities including interviewing and writing, photographing and videoing, editing, and reviewing. The improvement of media literacy is bound to lay a good foundation for future career in the media industry. Second, due to the characteristics of their major, foreign language students often actively read and pay attention to foreign information portals, radio broadcasts, newspapers and magazines, etc., especially keen on the emerging Internet media. However, in the Internet information that spreads at the speed of light and grows in geometric multiples, all kinds of information are in chaos and confusion. With the rise of "We Media", the fragmentation of network information is accelerated. Although college students have certain knowledge, there is still a certain gap between them and the stage of rational identification of foreign intelligence information. Especially in the face of religion, belief, culture, film and television and other aspects of information with negative political intention, they will often subtly be infected by it, and even go astray. As a result of being in a university, it will have an influence on the surrounding areas to form diffusion. Therefore, it is more necessary to conduct media literacy education for foreign language majors.

\section{WAYS TO IMPROVE MEDIA LITERACY IN FOREIGN LANGUAGE TEACHING IN COLLEGES AND UNIVERSITIES}

Media literacy education started in the UK in the 1930s and has achieved great development through continuous improvement. At present, many developed countries have incorporated media literacy education into their national education system, while China is still in the preliminary stage, or the stage of calling for it, and media literacy education in college foreign language teaching is in its infancy. In view of this situation, the following ways are suggested to improve students' media literacy in foreign language teaching in colleges and universities.

First, the media literacy education should be included in the foreign language teaching objectives of colleges and universities, and the reform of the current training plan for foreign language talents in colleges and universities should be explored. In the current undergraduate talent training programs, most universities are striving to build composite talents of "foreign language +". However, it is hard to find the keywords similar to media literacy in the training objectives, training requirements, basic optional courses or public optional courses. In the context of the omnimedia era, with emphasis on the cross and integration concept of new arts education, colleges and universities should focus on introducing courses related to the promotion of media literacy into foreign language talents training programs, or integrate relevant contents of media literacy into the courses and materials commonly used in traditional foreign language teaching, such as listening, reading from newspapers and periodicals, audio-visual and speaking, and selected news reading.

Second, we should integrate and improve the teaching staff of media and foreign languages. Nowadays, in the traditional foreign language teaching in universities, the professional English teachers lack the knowledge reserve of media; besides, the teachers of media major lack the professional English teaching ability. Therefore, in terms of the construction of the teacher team, it is necessary for teachers from both sides to strengthen their own weak areas and promote their mutual integration to form a joint teaching force, and encourage the foreign language teachers on regular payroll to conduct interdisciplinary academic studies or visiting research. In addition, we can employ professionals with multi-disciplinary backgrounds who are engaged in international news media in society to give guest lectures or give series lectures.

Third, it is necessary to explore and master the media theory and application practice. In terms of teaching, on the one hand, students should be exposed to classical theories of journalism, understand the relationship between foreign languages and media, understand the nature of media and the development trend at home and abroad, and get in touch with the latest international current affairs. At the same time, new media teaching means should be flexibly used to select the content that students are interested in, from inspiration to immersion, so that students can use media theory to analyze, edit or perform re-interpretation activities, so as to enhance the teaching interest to the greatest extent. It should be extensively connected with off-campus media companies to form a multi-practice base to conduct professional practice in summer and winter vacation or spare time, so that students can 
master the most cutting-edge information and technology needs [4].

Fourth, it is necessary build a good environment for promoting media literacy in various aspects. People are the product of the environment, and we can even say people are part of the environment. Building a good media environment in the School of Foreign Languages can not only cultivate students' interest in media, but also facilitate the good dissemination and diffusion of media. Relying on the School of Foreign Languages and the off-campus practice base, and taking into account technology and authority, students are jointly guided to carry out various appropriate media competitions. For example, two groups of traditional media and new media are formed to edit and report the common theme respectively. Another example is to set up their own radio stations, WeChat public accounts or Douyin accounts for various foreign language majors to edit and push on a rotating basis.

Fifth, we need to cultivate humanistic literacy and fundamentally nourish the promotion of media literacy. The essence of media literacy is humanistic literacy. Especially in today's context of media convergence, even the double-layer composite talents of foreign language and media are far from meeting the needs of the rapidly developing society. Both foreign language teaching and media teaching need the strong support of humanities. In particular, if you want to be an international media practitioner, you need comprehensive knowledge of politics, history, economy, culture and other fields at home and abroad as a reserve. In many fields, the ultimate competition is the competition of humane and cultural connotations.

\section{CONCLUSION}

At present, there is a phenomenon that an increasing number of foreign language graduates in China transfer their majors to media. For one thing, this is because of the rapid development of new media. For another, foreign language graduates have several advantages, such as their language ability, dual major background and easy entry into the international media field. Therefore, in view of the current foreign language teaching in colleges and universities, it is particularly critical to improve students' media literacy. Even if foreign language graduates do not make the transition to the media field, students who grew up in the new media era still need to have basic media literacy to cope with this era.

Generally speaking, there are many ways to improve students' media literacy in foreign language teaching in colleges and universities. This paper summarizes them from five aspects. First, it should be included in the training programs or teaching objectives of foreign language talents in colleges and universities. Only when it is included in the plan can it achieve long-term and stable development. The second is to enrich the teaching staff in this field, teach and influence students from the nearest distance, and increase the proportion of teachers who combine foreign language and media. The third is to explore and master media theory and application practice. We should use multimedia means to integrate teaching, expand the practice base to cultivate the ability of putting theory into practice. The fourth is to build a good environment to promote media literacy from various aspects. The environment has a great influence on students [5]. Good media education and improving atmosphere are crucial to the improvement of students' media literacy. The final aspect is to cultivate students' humanistic background comprehensively, shape their humanistic feelings, and fundamentally nourish and improve their media literacy, thus bringing about an all-round improvement of their overall quality.

\section{ABOUT THE AUTHOR:}

(1) Gao Yanjun, male, born in 1981, doctor, lecturer of School of Foreign Languages, Shandong Technology and Business University. Tel: 18563891570 E-mail: 18563891570@163.com

\section{REFERENCES}

[1] Yan L. Foreign language quality and composition of internationalized media talents -- An analysis of media specialized English demand [J], Modern Communication (Journal of Communication University of China), 2012(06),119-122.

[2] Li G, Zhu J, Zhang ST. The concept and path of integrated journalism and communication talents training [J], Youth Journalist, 2021(05),83-84.

[3] Wang H. Foreign language needs and teaching strategies of media majors under the background of education internationalization [J], Overseas English, 2014(23),87-89.

[4] Li XG. A study on media literacy education of foreign Language majors in colleges and universities based on Habermas communication theory [J], Journal of Inner Mongolia University of Finance and Economics, 2014(05),120-123.

[5] Zhang LN. Strategies for improving media literacy of high school students [J], West China Broadcasting TV, 2018 (22), 66-68. 